\title{
$\alpha$-Mangostin Induces Apoptosis and Cell Cycle Arrest in Oral Squamous Cell Carcinoma Cell
}

\author{
Hyun-Ho Kwak, ${ }^{1}$ In-Ryoung Kim, ${ }^{2}$ Hye-Jin Kim, ${ }^{3}$ \\ Bong-Soo Park, ${ }^{1}$ and Su-Bin Yu ${ }^{1}$ \\ ${ }^{1}$ BK21 PLUS Project, School of Dentistry, Pusan National University, Busandaehak-ro, 49, Mulguem-eup, Yangsan-si, \\ Gyeongsangnam-do 50612, Republic of Korea \\ ${ }^{2}$ Department of Oral Anatomy, School of Dentistry, Pusan National University, Busandaehak-ro, 49, Mulguem-eup, \\ Yangsan-si, Gyeongsangnam-do 50612, Republic of Korea \\ ${ }^{3}$ Department of Dental Hygiene, Dong-Eui University, 176 Eomgwang-ro, Busanjin-gu, Busan 47340, Republic of Korea \\ Correspondence should be addressed to Su-Bin Yu; ysb0811@gmail.com
}

Received 23 March 2016; Revised 5 June 2016; Accepted 14 June 2016

Academic Editor: Shao-Hsuan Kao

Copyright (c) 2016 Hyun-Ho Kwak et al. This is an open access article distributed under the Creative Commons Attribution License, which permits unrestricted use, distribution, and reproduction in any medium, provided the original work is properly cited.

\begin{abstract}
Mangosteen has long been used as a traditional medicine and is known to have antibacterial, antioxidant, and anticancer effects. Although the effects of $\alpha$-mangostin, a natural compound extracted from the pericarp of mangosteen, have been investigated in many studies, there is limited data on the effects of the compound in human oral squamous cell carcinoma (OSCC). In this study, $\alpha$-mangostin was assessed as a potential anticancer agent against human OSCC cells. $\alpha$-Mangostin inhibited cell proliferation and induced cell death in OSCC cells in a dose- and time-dependent manner with little to no effect on normal human PDLF cells. $\alpha$-Mangostin treatment clearly showed apoptotic evidences such as nuclear fragmentation and accumulation of annexin $\mathrm{V}$ and PI-positive cells on OSCC cells. $\alpha$-Mangostin treatment also caused the collapse of mitochondrial membrane potential and the translocation of cytochrome $\mathrm{c}$ from the mitochondria into the cytosol. The expressions of the mitochondria-related proteins were activated by $\alpha$-mangostin. Treatment with $\alpha$-mangostin also induced G1 phase arrest and downregulated cell cycle-related proteins (CDK/cyclin). Hence, $\alpha$-mangostin specifically induces cell death and inhibits proliferation in OSCC cells via the intrinsic apoptosis pathway and cell cycle arrest at the G1 phase, suggesting that $\alpha$-mangostin may be an effective agent for the treatment of OSCC.
\end{abstract}

\section{Introduction}

Oropharynx tumors (oral cancer) are caused by tobacco and alcohol consumption and high-risk human papillomavirus (HPV) infection. Oral squamous cell carcinoma (OSCC), which is the most common type of oral cancer and frequently arises from the mucosa of the oropharynx and oral cavity, is an increasing national health problem [1-3]. Despite advances in the diagnosis and treatment (chemotherapy, radiotherapy, and surgery) of oral cancer, the overall fiveyear survival rate has remained at $\sim 60 \%$ over the past two decades $[4,5]$.

The tropical fruit mangosteen (Garcinia mangostana Linn.) grows in Southeast Asia, and the pericarp of the mangosteen contains a variety of phytochemicals that are used as traditional medicines for disease management [6]. One of the phytochemical groups in the mangosteen pericarp is the xanthones, which are compounds that are associated with various biological activities including cardioprotective, antioxidant, anti-inflammatory, antibacterial, antiallergy, and anticancer activities [7]. Of all the mangosteen pericarpderived xanthones, $\alpha$-mangostin is the most abundant and has been shown to have potent anticancer effects against various types of cancer [8-13].

Apoptosis (type I programmed cell death) is the regulated death program that functions to maintain cellular homeostasis and eliminate damaged cells $[14,15]$. Apoptotic cells are known to exhibit various features including nuclear 
condensation, DNA fragmentation, membrane blebbing, and an increase in the permeability of cells [16]. $\alpha$-Mangostin was previously shown to induce apoptosis via mitochondrial dysfunction in human leukemia cells [17], while another study showed that $\alpha$-mangostin acts as an effective anticancer agent against pancreatic tumors in vitro and in vivo [18]. Other studies have demonstrated antiproliferative and apoptotic effects of $\alpha$-mangostin in head and neck squamous carcinoma cells $[19,20]$. The anticancer effects of $\alpha$-mangostin in human OSCC and the molecular mechanisms underlying these effects are poorly understood.

Therefore, in the present study, we examined whether $\alpha$-mangostin-induced cell death is intimately linked with apoptosis and cell cycle arrest in human OSCC.

\section{Methods}

2.1. Reagents and Cell Culture. Human OSCC cell lines (HSC2, HSC-3, and HSC-4) were provided by professor Sung-Dae Cho in the Department of Oral Pathology, School of Dentistry, Chonbuk National University (Jeonju, Korea). Human periodontal ligament fibroblast (PDLF) was purchased from Lonza (Basel, Switzerland). All OSCC and PDLF cells were cultured in Minimum Essential Medium/Earle's Balanced Salt Solution (MEM/EBSS) and Dulbecco's Modified Eagle Medium: Nutrient Mixture F-12 (DMEM/F-12), respectively, containing $4 \mathrm{mML}$-glutamine, $1.5 \mathrm{~g} / \mathrm{L}$ sodium bicarbonate, $4.5 \mathrm{~g} / \mathrm{L}$ glucose, and $1.0 \mathrm{mM}$ sodium pyruvate supplemented with 10\% fetal bovine serum (FBS) (Hyclone, Logan, UT) and $1 \%$ penicillin-streptomycin (WELGENE, Daegu, Korea). Cells were incubated at $37^{\circ} \mathrm{C}$ in a humidified $5 \% \mathrm{CO}_{2} / 95 \%$ air incubator. $\alpha$-Mangostin was purchased from Chromadex (Irvine, CA). MTT was purchased from Sigma (St. Louis, MO), and caspase-3, PARP, and p $21^{\text {wafl/cipl }}$ antibodies were purchased from Cell Signaling Technology (Beverly, MA). Cytochrome c, Bak, caspase-9, and GAPDH antibodies were purchased from Santa Cruz Biotechnology (Santa Cruz, CA). Goat anti-rabbit IgG and goat anti-mouse IgG antibodies were obtained from Enzo life sciences (Farmingdale, NY). A stock solution of $\alpha$-mangostin $(20 \mathrm{mM})$ was prepared in dimethyl sulfoxide (DMSO; Duchefa, Haarlem, Netherlands) and stored at $-20^{\circ} \mathrm{C}$ until use. The stock solution was diluted to the indicated concentrations with MEM/EBSS when needed. At 70-80\% confluence, cells were treated with various concentrations of $\alpha$-mangostin for the indicated time-periods. Cells grown in culture medium containing the equivalent amount of DMSO without $\alpha$-mangostin served as controls. The final concentrations of DMSO in these experiments were $0.002-0.1 \%(\mathrm{v} / \mathrm{v})$.

2.2. MTT Assay for Cell Viability. The viability of HSC-2, HSC-3, and HSC-4 cells was determined using an MTT assay. The OSCC cells were cultured in 96-well plates $\left(1 \times 10^{4}\right.$ cells/well) and incubated in the presence of various concentrations of $\alpha$-mangostin ( $0-10 \mu \mathrm{M})$ for different time-periods. After the treatment was terminated, the culture medium was removed and $100 \mu \mathrm{L} \mathrm{MTT}(500 \mathrm{mg} / \mathrm{mL})$ was added to each well. The cells were incubated for $4 \mathrm{~h}$ at $37^{\circ} \mathrm{C}$, after which the resulting formazan crystals were solubilized in DMSO (150 $\mu \mathrm{L} /$ well) with constant shaking for $15 \mathrm{~min}$. The colored solution was quantified at $620 \mathrm{~nm}$ using an ELISA reader (Tecan, Männedorf, Switzerland). Cell viability was calculated as a percentage relative to controls. The reported data were obtained from at least three independent experiments.

\subsection{Hoechst Staining for Morphological Assessment of Apop-} tosis. Vehicle- and $\alpha$-mangostin-treated cells were harvested and cytocentrifuged onto a glass slide. The cells were stained with $10 \mu \mathrm{g} / \mathrm{mL}$ Hoechst 33342 (Sigma) for 10 minutes at $37^{\circ} \mathrm{C}$ in the dark before being washed with PBS. The slides were mounted with glycerol and the cells were examined under a fluorescence microscope (Carl Zeiss, Göettingen, Germany). The number of cells exhibiting a condensed or fragmented nucleus was determined from random sampling of $3 \times 10^{2}$ cells per experiment by a blinded observer.

\subsection{Flow Cytometry Analysis for Apoptosis, Mitochondrial} Transmembrane Potential $(\Delta \Psi m)$ Measurements, and Cell Cycle. To quantify apoptosis in the early, late stage and necrosis, cells were seeded in $60 \mathrm{~mm}$ dishes $\left(3 \times 10^{5}\right.$ cells/dish), cultured with $\alpha$-mangostin for $24 \mathrm{~h}$, and harvested and processed for apoptosis assay using annexin V-FITC apoptosis detection kit (Enzo, Farmingdale, NY), following indicated protocol specified by the manufacturer and examined using a CYTOMICS FC500 flow cytometer system (Beckman Coulter, Porterville, CA). The data were analyzed using MultiCycle software that allows for simultaneous analyses for cell cycle parameters and apoptosis. The MMP (mitochondrial membrane potential) was measured using $\mathrm{DiOC}_{6}$ (Molecular Probes, Eugene, OR) dye. The cells were loaded with a final concentration of $1 \mu \mathrm{M} \mathrm{DiOC}_{6}$ solution at $37^{\circ} \mathrm{C}$ for $30 \mathrm{~min}$ and then analyzed using flow cytometry.

2.5. Immunofluorescent Staining for Detection of Cytochrome c Translocation. The cells were plated on coverslips and treated with $\alpha$-mangostin. After $24 \mathrm{~h}$, the cells were stained with $50 \mathrm{nM}$ MitoTracker Red at $37^{\circ} \mathrm{C}$ for $30 \mathrm{~min}$. After washing twice with PBS, the cells were fixed with $4 \%$ paraformaldehyde (PFA) in PBS for $15 \mathrm{~min}$ and washed three times with PBS. After permeabilization with $0.1 \%$ Triton X-100 and blocking with $1 \%$ BSA in PBS for $30 \mathrm{~min}$, the cells were incubated with primary antibodies in $1 \%$ BSA overnight at $4^{\circ} \mathrm{C}$. After washing with PBS, cells were incubated with FITC-conjugated secondary antibodies in 1\% BSA-PBS for 1 hour and rinsed with PBS. The cells were imaged using a confocal microscopy (Zeiss LSM 750 laser-scanning confocal microscope; Carl Zeiss, Göettingen, Germany).

2.6. Western Blot Analysis. Cells $\left(2 \times 10^{6}\right)$ were washed twice with ice-cold PBS, resuspended in ice-cold lysis buffer (CST, Boston, MA), and incubated at $4^{\circ} \mathrm{C}$ for $1 \mathrm{~h}$. The resulting lysates were centrifuged at $24 \times 3.75 \mathrm{~g}$ for $30 \mathrm{~min}$ at $4^{\circ} \mathrm{C}$. The protein concentrations of the lysates were determined using a Bradford protein assay (Bio-Rad, Richmond, CA). Lysates ( $25 \mu \mathrm{g}$ protein/lane) were resolved by $10 \%$ SDS (sodium dodecyl sulfate)/PAGE. The proteins were transferred to 


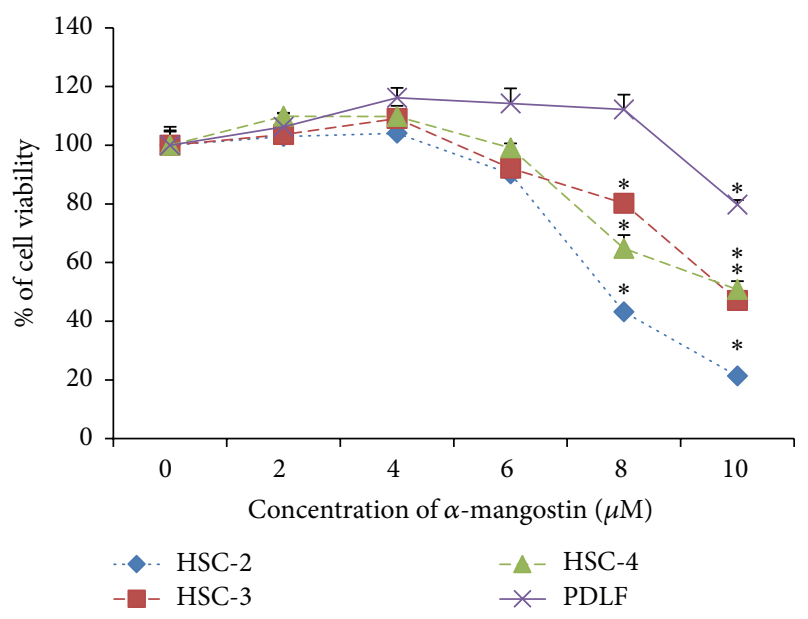

(a)

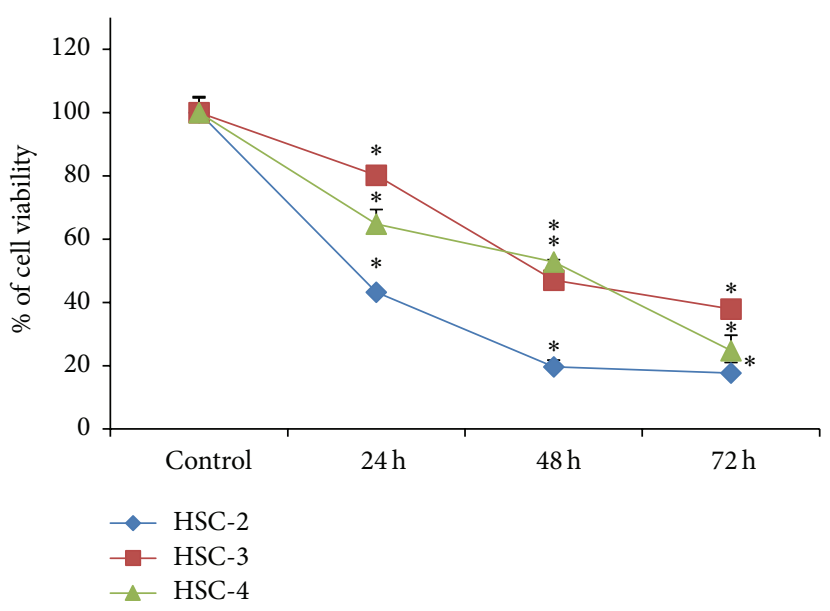

(b)

FIGURE 1: Effect of $\alpha$-mangostin on cell viability in OSCC and PDLF cells. (a) OSCC and PDLF cells were treated with $\alpha$-mangostin (0$10 \mu \mathrm{M}$ ) for $24 \mathrm{~h}$. (b) OSCC cells were treated with $8 \mu \mathrm{M} \alpha$-mangostin for $24 \mathrm{~h}-72 \mathrm{~h}$. Data represent viability calculated relative to vehicle control-treated cells and are expressed as means \pm SE from at least three experiments; ${ }^{*} p<0.05$ versus untreated cells.
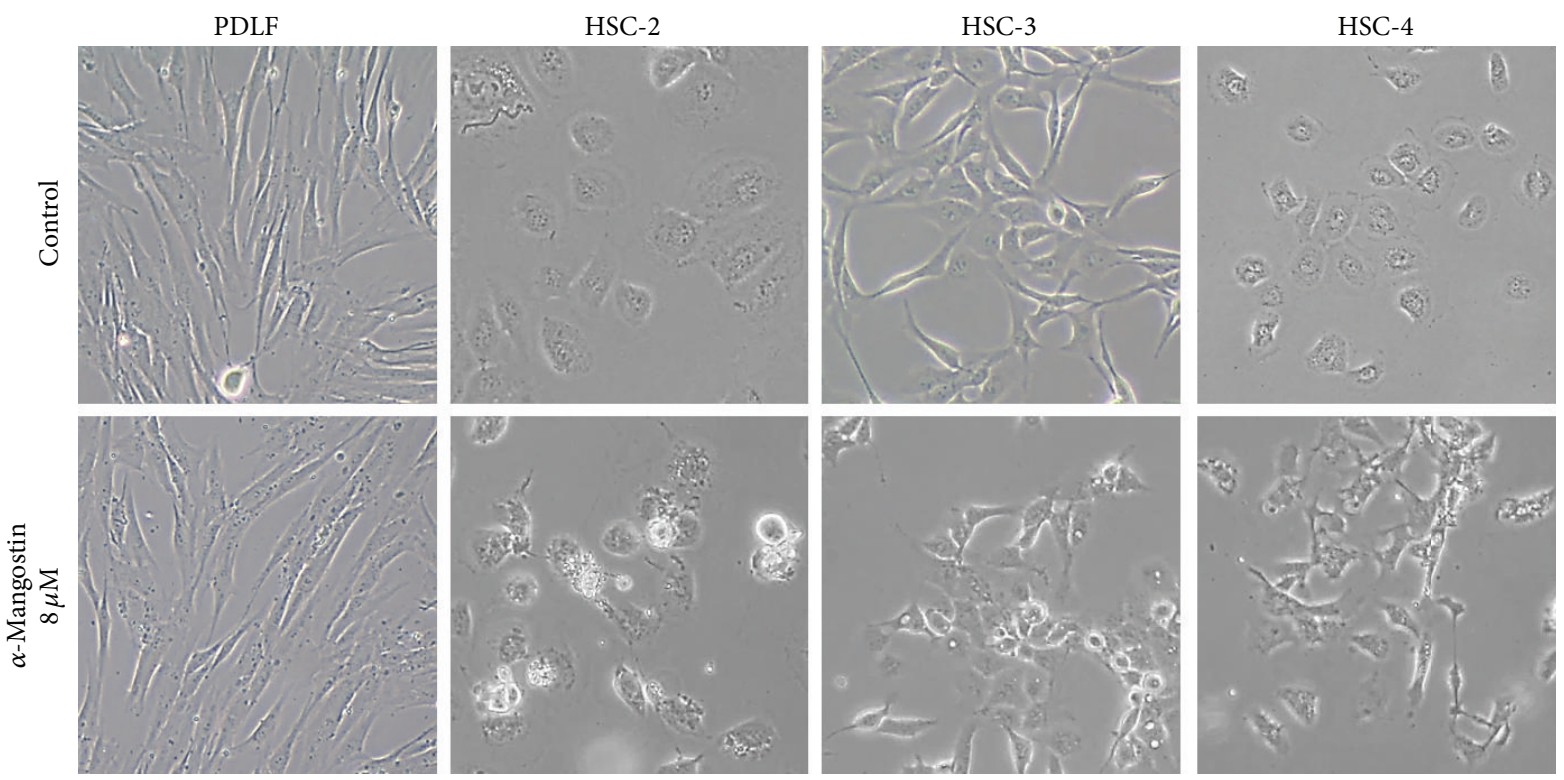

FIGURE 2: Morphological changes in $\alpha$-mangostin-treated PDLF and OSCC cells. Cells were treated with $\alpha$-mangostin for 24 h. Images were acquired with an optical microscope at 20x magnification.

polyvinylidene fluoride (PVDF) membranes (Millipore, Billerica, MA) which were then blocked before being incubated with the appropriate primary antibodies. Immunostaining with secondary antibodies was detected using SuperSignal West Femto substrate (Pierce, Rockford, IL).

2.7. Statistical Analysis. Reported data represent mean \pm SE. Statistical significances between groups were analyzed using one-way analysis of variance (ANOVA) and Dunnett's comparison. Differences with probability $(p)$ values $<0.05$ were considered statistically significant.

\section{Results}

3.1. $\alpha$-Mangostin Induces Apoptotic Cell Death in Human Oral Squamous Cell Carcinoma Cell Lines. To investigate the cytotoxic effect of $\alpha$-mangostin, human OSCC cells (HSC-2, HSC-3, and HSC-4) and normal human periodontal ligament fibroblast (PDLF) cells were cultured with various concentrations of $\alpha$-mangostin for $24 \mathrm{~h}$. Cell viability was assessed using a MTT assay, which revealed that $\alpha$-mangostin treatment resulted in a decrease in OSCC cell viability in a doseand time-dependent manner without affecting normal PDLF cells (Figure 1). The $\mathrm{IC}_{50} \mathrm{~s}$ of $\alpha$-mangostin in OSCC cell types 


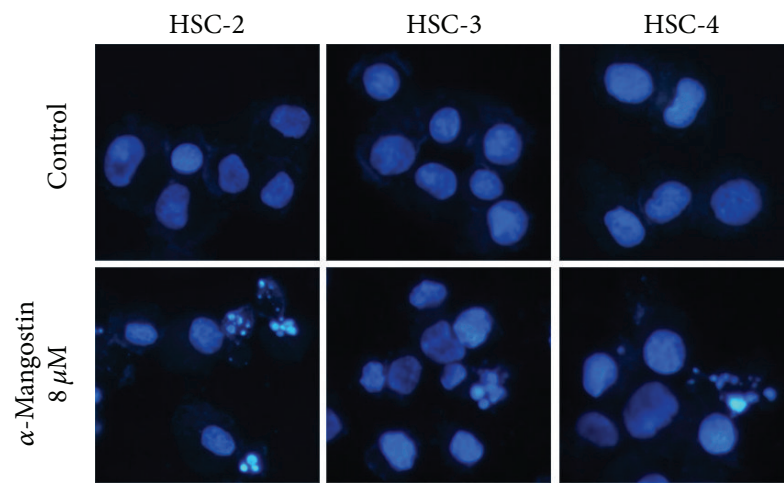

(a)
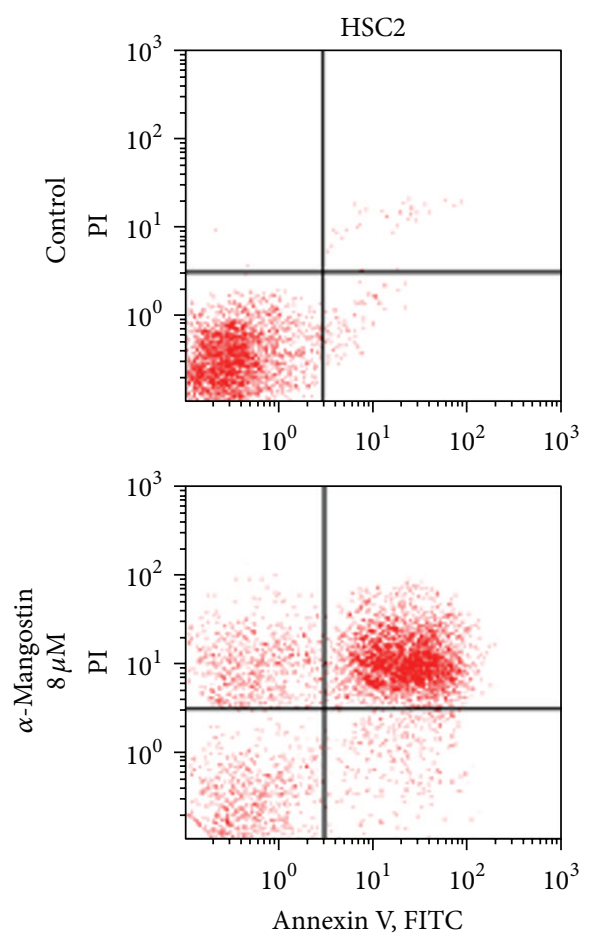

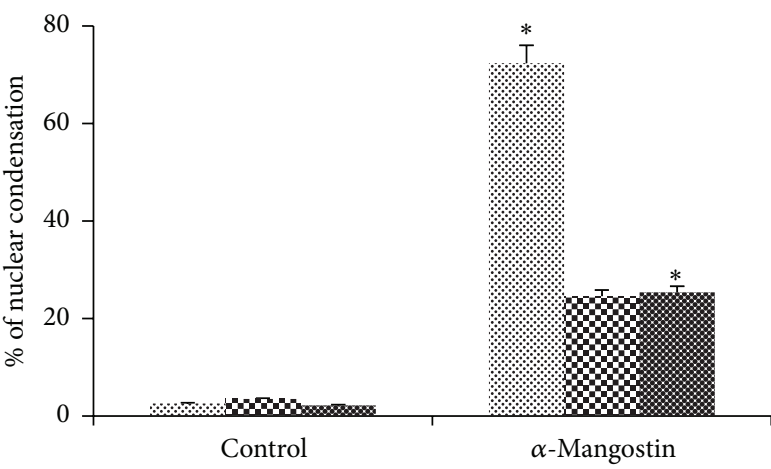

: HSC2 HSC4

(b)
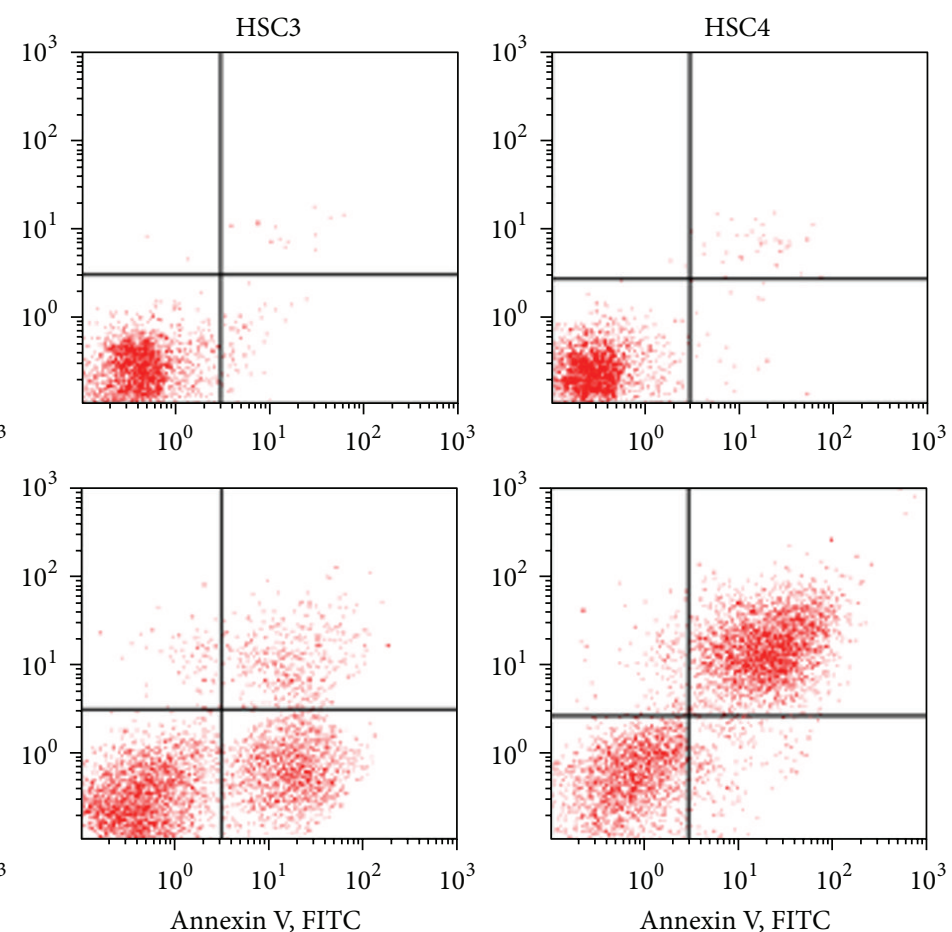

(c)

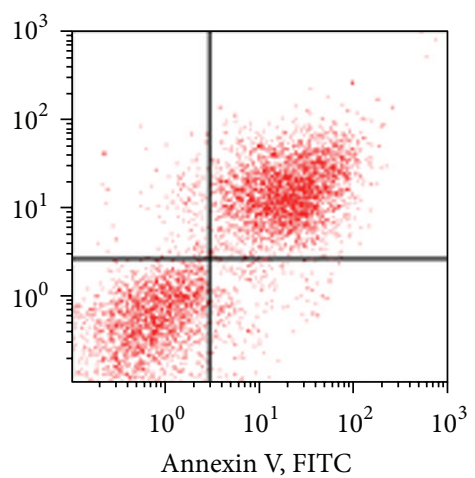

FIGURE 3: Induction of cell death in $\alpha$-mangostin-treated OSCC cells via apoptosis. (a, b) After 24 h of treatment with $\alpha$-mangostin, OSCC cells were stained with Hoechst and observed under a fluorescence microscope. (c) Analysis of apoptotic cells in untreated and $\alpha$-mangostintreated cells by annexin V and PI staining. Values represent mean \pm SE of three independent experiments; ${ }^{*} p<0.05$ versus untreated cells.

(HSC-2, HSC-3, and HSC-4) were 8-10 $\mu \mathrm{M}$ (Figure 1(a)). $\alpha$ Mangostin was also found to induce morphological changes such as membrane blebbing, cell shrinkage, and rounding in OSCC cells, but not in PDLF cells (Figure 2). These findings suggest that $\alpha$-mangostin treatment induces cell death and morphological changes in OSCC cells.

To further investigate the biological mechanism underlying $\alpha$-mangostin-induced cell death, cells were analyzed for the presence of apoptosis using Hoechst staining and flow cytometry. Following Hoechst staining, untreated cells exhibited round nuclei, while some $\alpha$-mangostin-treated cells exhibited nuclear condensation and fragmentation. $\alpha$ Mangostin had a significantly stronger effect in HSC-2 cells than in the other cell types (Figures 3(a) and 3(b)). To ascertain the dead ratio of OSCC cells, the cells were stained with annexin $\mathrm{V}$ and PI solution and analyzed by flow cytometry, and cells were treated with $8 \mu \mathrm{M} \alpha$-mangostin for $24 \mathrm{~h}$. Compared with untreated cells, $\alpha$-mangostin-treated cells exhibited significant increases in annexin V and PI-positive staining that indicated apoptosis (Figure 3(c)). Notably, the HSC-2 cells showed the highest apoptosis rate among the treated cells. 

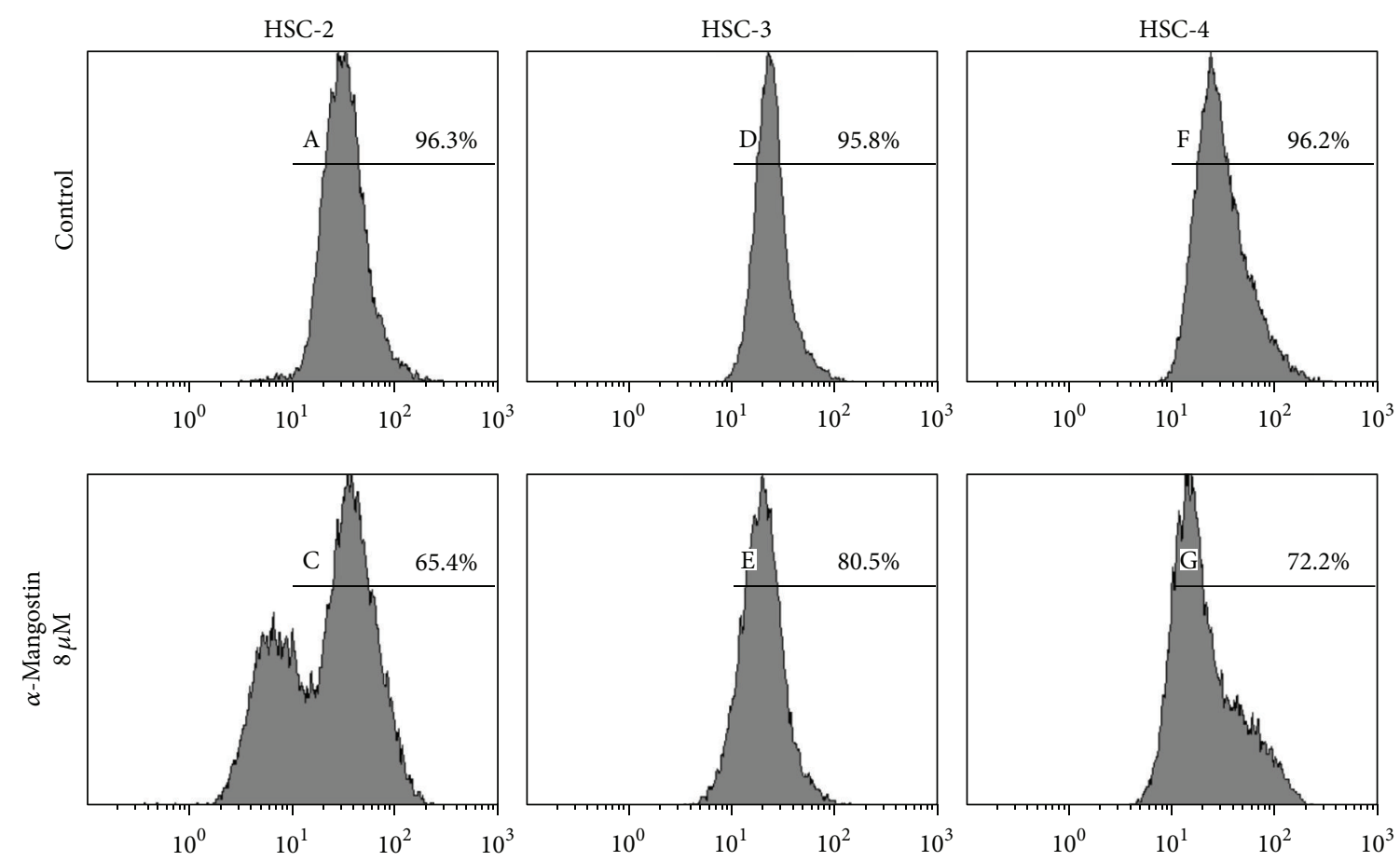

FIGURE 4: Collapse of mitochondrial membrane potential $(\Delta \Psi m)$ in $\alpha$-mangostin-induced apoptosis. Cells treated with $8 \mu \mathrm{M} \alpha$-mangostin for $24 \mathrm{~h}$ and incubated with $1 \mu \mathrm{M} \mathrm{DiOC}_{6}$ were analyzed by flow cytometry.

3.2. Mitochondrial Dysfunction and Caspase-Mediated Apoptosis Induced by $\alpha$-Mangostin. The intrinsic pathway of apoptosis is characterized by a key role for mitochondria, specifically by the dissipation of mitochondrial membrane potential $(\Delta \Psi m)$, which is associated with mitochondrial dysfunction [21, 22]. Changes in $\Delta \Psi m$ in $\alpha$-mangostin-induced apoptosis were thus assessed using $\mathrm{DiOC}_{6}$. $\alpha$-Mangostin was found to trigger a loss in $\Delta \Psi m$ in the OSCC cell lines compared to the untreated controls (Figure 4). Loss in $\Delta \Psi m$ may result in the release of cytochrome $\mathrm{c}$ into the cytosolic fraction and the translocation of cytochrome $\mathrm{c}$ was therefore subsequently assessed using immunofluorescent staining. As shown in Figure 5, treatment with $8 \mu \mathrm{M} \alpha$-mangostin induced the release of cytochrome $c$ from the mitochondria into the cytosol in OSCC cells, whereas in the untreated cells, the cytochrome $\mathrm{c}$ staining colocalized with the MitoTracker signal.

To elucidate the molecular mechanisms underlying $\alpha$ mangostin-induced apoptosis, the expression levels of apoptosis-associated proteins such as Bak, caspase-9, caspase3 , and PARP were assessed using western blot analysis. The protein expression levels of Bak, a proapoptotic Bcl-2 family member, were found to increase in response to $\alpha$ mangostin, while the expression levels of caspase-9, caspase3 , and PARP (normalized to GAPDH expression) decreased. The expression levels of the cleaved forms of caspase- 3 and PARP, in particular, were shown to increase significantly in HSC-2 cells (Figure 6). These results clearly demonstrate that $\alpha$-mangostin-induced apoptosis involves the intrinsic apoptosis pathway and caspase-cascades.
3.3. $\alpha$-Mangostin Regulates Cell Cycle Distribution through a G1 Phase Arrest. To assess whether $\alpha$-mangostin arrests specific cell cycles, OSCC cells were treated with $8 \mu \mathrm{M} \alpha$ mangostin for 6,12 , and $24 \mathrm{~h}$. Cell cycle population analysis was subsequently performed using flow cytometry after PI staining. The results of this analysis (Figure $7(a)$ ) show that the cell distribution in the G1 phase became significantly stagnated in a time-dependent manner in the mangostintreated group compared to the vehicle-treated group. The expression levels of cell cycle regulatory proteins including CDK4 (cyclin-dependent kinase-4), CDK2, cyclin D3, cyclin $\mathrm{E}$, and $\mathrm{p} 27^{\mathrm{kipl}}$ were also assessed. Each CDK/cyclin complex is involved in the progression or transition of the cell cycle. Cyclin D interacts with CDK4 and cyclin E interacts with CDK2 to modulate cell cycle distribution in the G1 phase [23, 24]. Figure 7(b) shows that $\alpha$-mangostin downregulated the expression of CDK4, CDK2, cyclin D3, and cyclin E, whereas p2 $7^{\mathrm{kipl}}$ and $\mathrm{p} 21^{\text {wafl/cipl }}$, a CDK inhibitor, were upregulated by $\alpha$-mangostin in a time-dependent manner. The p $27^{\text {kip1 }}$ protein, however, was not expressed in HSC-3 cells. These data reveal that $\alpha$-mangostin leads to the arrest of the cell cycle at the G1 phase by inhibiting $\mathrm{CDK} /$ cyclin complex activities.

\section{Discussion}

The subsurface phytochemicals of the mangosteen pericarp include over 200 xanthones. The xanthones exhibit notable biological activities $[7,25]$ and among the many xanthone compounds, $\alpha$-mangostin, $\beta$-mangostin, $\gamma$-mangostin, and 

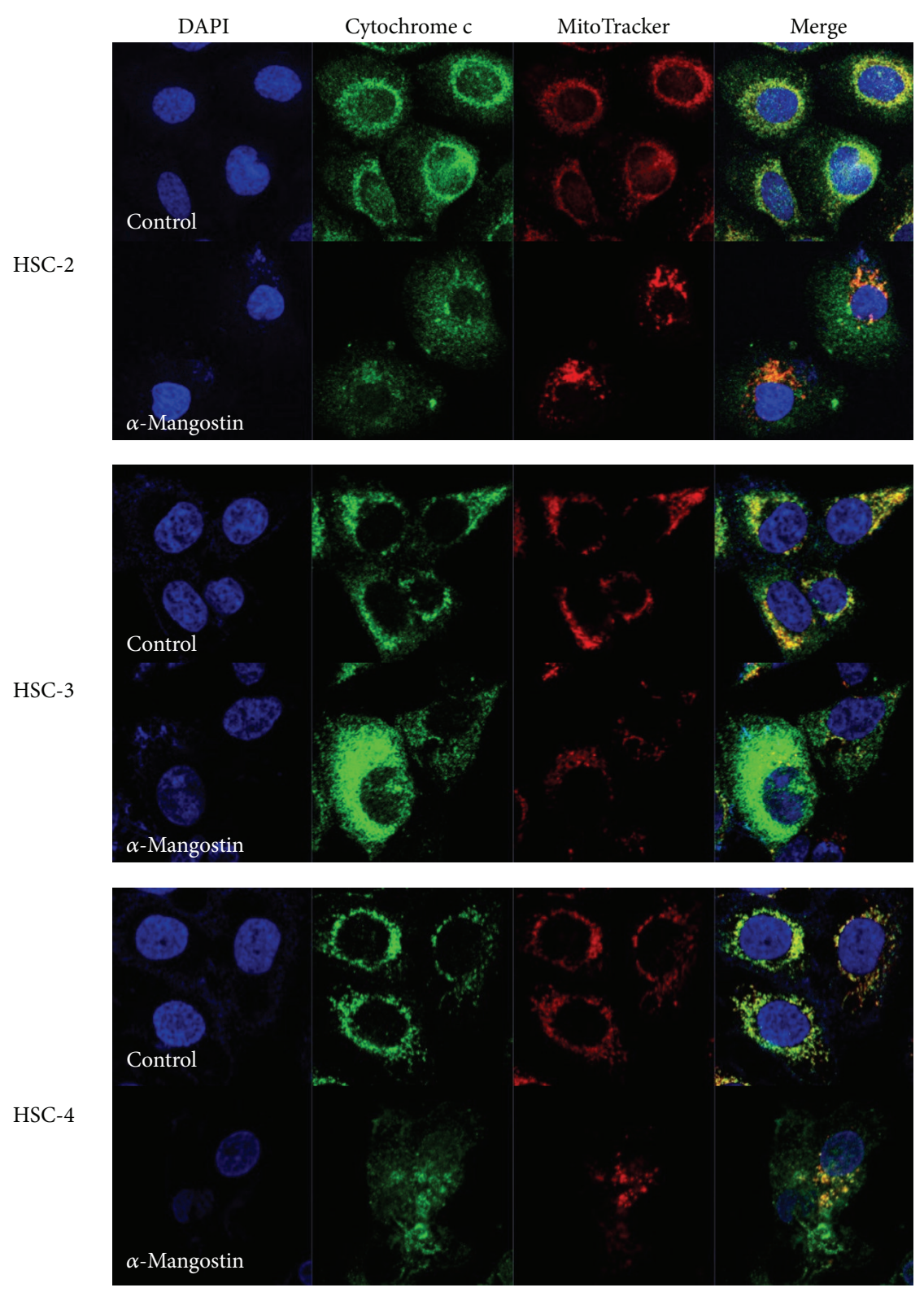

FIGURE 5: $\alpha$-Mangostin-induced translocation of cytochrome $\mathrm{c}$ from mitochondria into the cytosolic fraction in OSCC cells. Cells were incubated with $8 \mu \mathrm{M} \alpha$-mangostin for $24 \mathrm{~h}$ before being stained with MitoTracker (red), cytochrome c (green), and DAPI (blue) to visualize mitochondria, cytochrome $c$, and nuclei, respectively. Images were acquired by confocal microscopy.

gartanin are the most frequently researched [26]. Of these compounds, $\alpha$-mangostin was shown to have the strongest apoptotic activity in human melanoma cells and, compared to other similar compounds, $\alpha$-mangostin was shown to be the most effective agent in human cancer cell lines [27, 28]. $\alpha$-Mangostin has also been reported to act as an anticancer agent against various types of cancer cells including canine osteosarcoma cells, human colorectal cancer cells, and pancreatic cancer cells $[6,29-32]$. This suggests that $\alpha$-mangostin may be considered a prospective anticancer agent; however, the biological mechanism underlying $\alpha$-mangostin-induced cell death in human OSCC cell lines has not been well studied.
In the present study, we report that $\alpha$-mangostin has antitumor effects against the human OSCC cell lines HSC-2, HSC-3, and HSC-4. The observed antitumor effects were accompanied by the inhibition of cell proliferation, the acceleration of mitochondria-controlled apoptosis, and cell cycle arrest with no toxicity in normal human PDLF cells. In our preliminary work, the cytotoxicities of $\alpha$-mangostin and gartanin, both extracts of the mangosteen pericarp, were compared in human OSCC cells, and $\alpha$-mangostin was found to have more potent cytotoxic effects than gartanin in OSCC cell lines. In these preliminary experiments, $\alpha$-mangostin was also shown to inhibit cell viability in a dose- and timedependent manner and to induce morphological changes in 


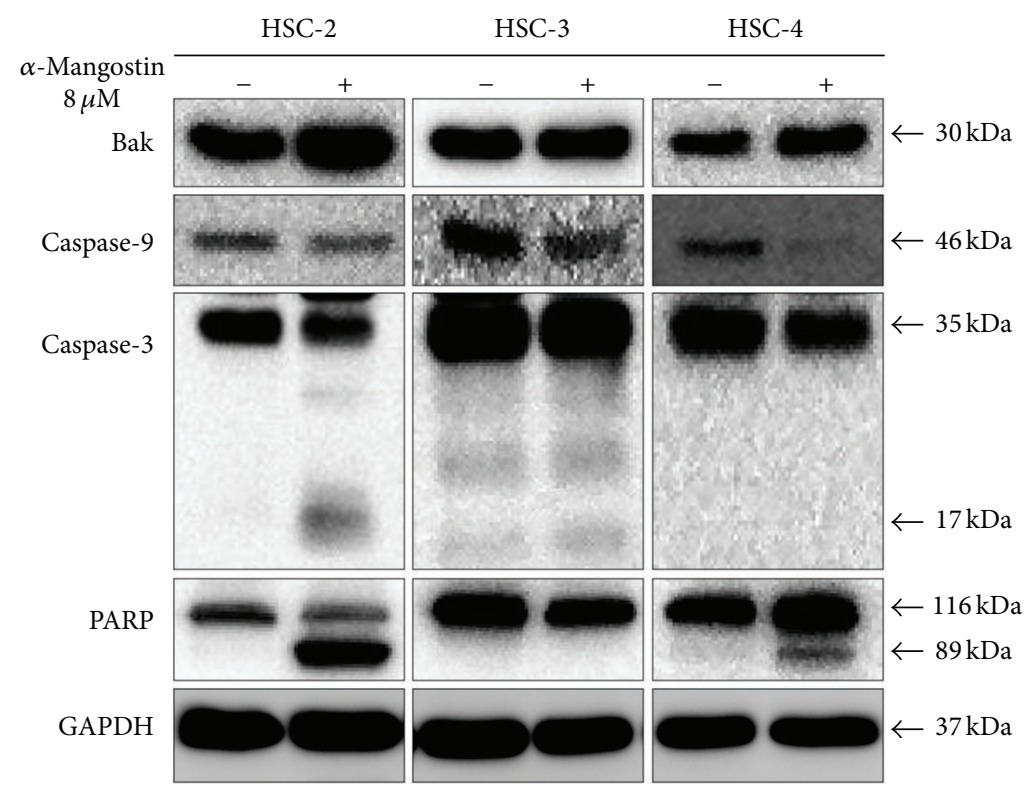

FIGURE 6: Activation of apoptosis-related proteins following $\alpha$-mangostin treatment of OSCC cells. OSCC cells treated with $8 \mu \mathrm{M} \alpha$ mangostin were shown by western blotting to exhibit altered expression of apoptosis-associated proteins (Bak, caspase-9, caspase-3, and PARP).

human OSCC cell lines but not in normal PDLF cells under the same conditions (Figures 1 and 2). Among the three human OSCC cell lines, HSC-2 cells were shown to be most sensitive to $\alpha$-mangostin.

We furthermore clarified using Hoechst staining and flow cytometry with annexin $\mathrm{V}$ and PI staining that $\alpha$-mangostin does induce apoptosis in human OSCC cells (Figure 3). Apoptosis is known to occur via two principal pathways: the extrinsic pathway is activated by death receptor stimulation, while the intrinsic pathway responds to DNA damage and other kinds of stimuli that are dominated by mitochondria $[14,33]$. Mitochondria play a pivotal role in the apoptotic machinery, and when the intrinsic pathway is activated, a sequence of events is triggered. These events include the depolarization of the MMP, the release of cytochrome $\mathrm{c}$ from mitochondria into the cytoplasm, and significant activation of caspases involved in the intrinsic pathway [34]. A number of studies have demonstrated that $\alpha$-mangostin induces apoptosis through the stimulation of mitochondrial functions $[11,12,17]$. In this study, we further demonstrated that $\alpha$ mangostin also induces apoptosis in human OSCC cells via $\Delta \Psi m$ depolarization and the release of cytochrome $c$, hallmarks of the mitochondrial pathway (Figures 4 and 5). The expressions of Bak, caspase, and PARP, which are considered critical regulators of apoptosis, were found to be activated by $\alpha$-mangostin treatment (Figure 6), while Bcl-2 expression was not detected in the OSCC cells. In these experiments too, $\alpha$-mangostin was found to have the most pronounced effect on HSC-2 cells compared with the other OSCC cells.

Cell cycle regulation is essential to the survival, proliferation, and differentiation of cells, and cell cycle dysregulation may lead to carcinogenesis [35, 36]. $\alpha$-Mangostin-induced cell cycle arrest at the G1 phase has been observed in prostate cancer, human breast cancer, and colon cancer $[8$, 37, 38]. Similarly, in our study, $\alpha$-mangostin treatment led to an accumulation of cells in the G1 phase accompanied by upregulation of the expression of p27 $7^{\mathrm{kipl}}$ and $\mathrm{p} 21^{\text {wafl/cipl }}$, a known CDK inhibitor. The cyclin/CDK complexes (controllers of the cell cycle), however, were downregulated by $\alpha$-mangostin treatment in a time-dependent manner (Figure 7).

The findings of the present study demonstrate that $\alpha$ mangostin induces apoptosis in human OSCC cells and that this apoptotic cell death is accompanied by the dysregulation of mitochondrial function as well as cell cycle arrest. These findings provide evidence in support of $\alpha$-mangostin as a novel, potential anticancer agent.

\section{Conclusions}

The present study described that $\alpha$-mangostin could be a potential anticancer agent for human OSCC and provides valuable data for the development of a novel anticancer strategy.

\section{Competing Interests}

The authors declare that there is no conflict of interests regarding the publication of this paper.

\section{Authors' Contributions}

The authors contributed equally to this work. 


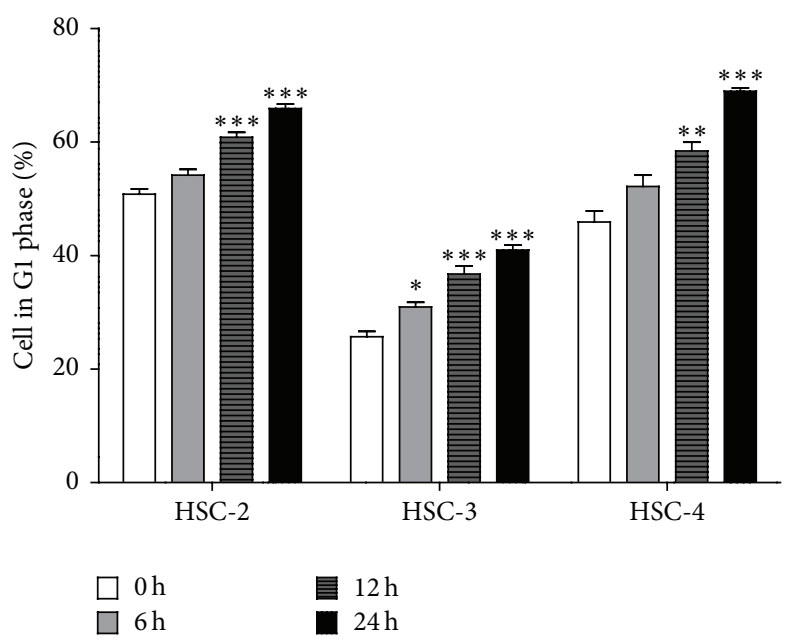

(a)
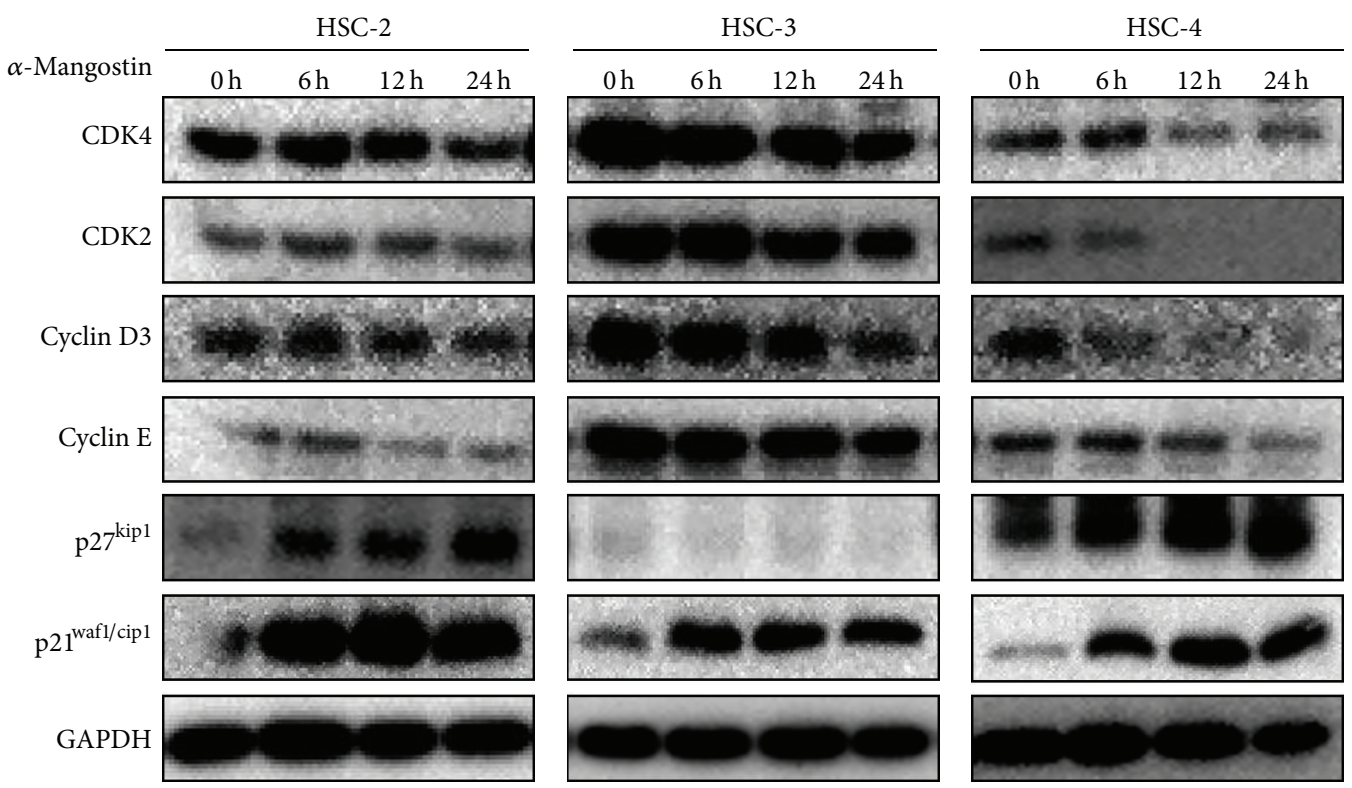

(b)

Figure 7: $\alpha$-Mangostin arrests the cell cycle G1 phase in a time-dependent manner. Cells were treated with $8 \mu \mathrm{M} \alpha$-mangostin for 6 , 12, and $24 \mathrm{~h}$ before being subjected to (a) cell cycle distribution analysis by flow cytometry and (b) western blotting to assess the expression levels of cell cycle-associated proteins (CDK4, CDK2, cyclin D3, cyclin E, p2 $7^{\text {kip1 }}$, and p2 $1^{\text {wafl/cipl }}$ ) normalized to GAPDH expression. Values represent mean \pm SE of three independent experiments; ${ }^{*} p<0.05$ versus untreated cells; ${ }^{* *} p<0.01$ versus untreated cells; ${ }^{* * *} p<0.001$ versus untreated cells.

\section{Acknowledgments}

This work was supported by a 2-Year Research Grant of Pusan National University.

\section{References}

[1] S.-F. Chen, S. Nien, C.-H. Wu, C.-L. Liu, Y.-C. Chang, and Y.-S. Lin, "Reappraisal of the anticancer efficacy of quercetin in oral cancer cells," Journal of the Chinese Medical Association, vol. 76, no. 3, pp. 146-152, 2013.

[2] A. K. Chaturvedi, E. A. Engels, W. F. Anderson, and M. L. Gillison, "Incidence trends for human papillomavirus-related and -unrelated oral squamous cell carcinomas in the United States," Journal of Clinical Oncology, vol. 26, no. 4, pp. 612-619, 2008.

[3] S. Warnakulasuriya, "Prognostic and predictive markers for oral squamous cell carcinoma: the importance of clinical, pathological and molecular markers," Saudi Journal of Medicine and Medical Sciences, vol. 2, no. 1, pp. 12-16, 2014.

[4] R. B. Bell, D. Kademani, L. Homer, E. J. Dierks, and B. E. Potter, "Tongue cancer: is there a difference in survival compared with other subsites in the oral cavity?" Journal of Oral and Maxillofacial Surgery, vol. 65, no. 2, pp. 229-236, 2007.

[5] A. Jemal, R. Siegel, E. Ward et al., "Cancer statistics, 2006," CA: A Cancer Journal for Clinicians, vol. 56, no. 2, pp. 106-130, 2006. 
[6] Q. Xu, J. Ma, J. Lei et al., " $\alpha$-Mangostin suppresses the viability and epithelial-mesenchymal transition of pancreatic cancer cells by downregulating the PI3K/Akt pathway," BioMed Research International, vol. 2014, Article ID 546353, 12 pages, 2014.

[7] J. Pedraza-Chaverri, N. Cárdenas-Rodríguez, M. OrozcoIbarra, and J. M. Pérez-Rojas, "Medicinal properties of mangosteen (Garcinia mangostana)," Food and Chemical Toxicology, vol. 46, no. 10, pp. 3227-3239, 2008.

[8] J. J. Johnson, S. M. Petiwala, D. N. Syed et al., " $\alpha$-mangostin, a xanthone from mangosteen fruit, promotes cell cycle arrest in prostate cancer and decreases xenograft tumor growth," Carcinogenesis, vol. 33, no. 2, pp. 413-419, 2012.

[9] P. Li, W. Tian, and X. Ma, "Alpha-mangostin inhibits intracellular fatty acid synthase and induces apoptosis in breast cancer cells," Molecular Cancer, vol. 13, no. 1, article 138, 2014.

[10] J. J. Wang, B. J. S. Sanderson, and W. Zhang, "Cytotoxic effect of xanthones from pericarp of the tropical fruit mangosteen (Garcinia mangostana Linn.) on human melanoma cells," Food and Chemical Toxicology, vol. 49, no. 9, pp. 2385-2391, 2011.

[11] S.-C. Hsieh, M.-H. Huang, C.-W. Cheng, J.-H. Hung, S.-F. Yang, and Y.-H. Hsieh, " $\alpha$-mangostin induces mitochondrial dependent apoptosis in human hepatoma SK-Hep-1 cells through inhibition of p38 MAPK pathway," Apoptosis, vol. 18, no. 12, pp. 1548-1560, 2013.

[12] A. Sato, H. Fujiwara, H. Oku, K. Ishiguro, and Y. Ohizumi, " $\alpha$-Mangostin induces $\mathrm{Ca}^{2+}$-ATPase-dependent apoptosis via mitochondrial pathway in PC12 cells," Journal of Pharmacological Sciences, vol. 95, no. 1, pp. 33-40, 2004.

[13] R. Watanapokasin, F. Jarinthanan, Y. Nakamura, N. Sawasjirakij, A. Jaratrungtawee, and S. Suksamrarn, "Effects of $\alpha$-mangostin on apoptosis induction of human colon cancer," World Journal of Gastroenterology, vol. 17, no. 16, pp. 2086-2095, 2011.

[14] N. Hail Jr., B. Z. Carter, M. Konopleva, and M. Andreeff, "Apoptosis effector mechanisms: a requiem performed in different keys," Apoptosis, vol. 11, no. 6, pp. 889-904, 2006.

[15] D. E. Fisher, "Apoptosis in cancer therapy: crossing the threshold," Cell, vol. 78, no. 4, pp. 539-542, 1994.

[16] I. Tedesco, M. Russo, S. Bilotto et al., "Dealcoholated red wine induces autophagic and apoptotic cell death in an osteosarcoma cell line," Food and Chemical Toxicology, vol. 60, pp. 377-384, 2013.

[17] K. Matsumoto, Y. Akao, H. Yi et al., "Preferential target is mitochondria in $\alpha$-mangostin-induced apoptosis in human leukemia HL60 cells," Bioorganic \& Medicinal Chemistry, vol. 12, no. 22, pp. 5799-5806, 2004.

[18] B. B. Hafeez, A. Mustafa, J. W. Fischer et al., " $\alpha$-Mangostin: a dietary antioxidant derived from the pericarp of Garcinia mangostana L. inhibits pancreatic tumor growth in xenograft mouse model," Antioxidants \& Redox Signaling, vol. 21, no. 5, pp. 682-699, 2014.

[19] R. Kaomongkolgit, "Alpha-mangostin suppresses MMP-2 and MMP-9 expression in head and neck squamous carcinoma cells," Odontology, vol. 101, no. 2, pp. 227-232, 2013.

[20] R. Kaomongkolgit, N. Chaisomboon, and P. Pavasant, "Apoptotic effect of alpha-mangostin on head and neck squamous carcinoma cells," Archives of Oral Biology, vol. 56, no. 5, pp. 483490, 2011.

[21] P.-C. Hsu, Y.-T. Huang, M.-L. Tsai, Y.-J. Wang, J.-K. Lin, and M.-H. Pan, "Induction of apoptosis by shikonin through coordinative modulation of the Bcl-2 family, p27, and p53, release of cytochrome c, and sequential activation of caspases in human colorectal carcinoma cells," Journal of Agricultural and Food Chemistry, vol. 52, no. 20, pp. 6330-6337, 2004.

[22] C.-C. Lu, J.-S. Yang, J.-H. Chiang et al., "Cell death caused by quinazolinone $\mathrm{HMJ}-38$ challenge in oral carcinoma CAL 27 cells: dissections of endoplasmic reticulum stress, mitochondrial dysfunction and tumor xenografts," Biochimica et Biophysica Acta-General Subjects, vol. 1840, no. 7, pp. 23102320, 2014.

[23] T. M. Pitts, S. L. Davis, S. G. Eckhardt, and E. L. BradshawPierce, "Targeting nuclear kinases in cancer: development of cell cycle kinase inhibitors," Pharmacology \& Therapeutics, vol. 142, no. 2, pp. 258-269, 2014.

[24] J. Cicenas, K. Kalyan, A. Sorokinas et al., "Highlights of the latest advances in research on CDK inhibitors," Cancers, vol. 6, no. 4, pp. 2224-2242, 2014.

[25] Y. Akao, Y. Nakagawa, M. Iinuma, and Y. Nozawa, "Anticancer effects of xanthones from pericarps of mangosteen," International Journal of Molecular Sciences, vol. 9, no. 3, pp. 355370, 2008.

[26] T. Shan, Q. Ma, K. Guo et al., "Xanthones from mangosteen extracts as natural chemopreventive agents: potential anticancer drugs," Current Molecular Medicine, vol. 11, no. 8, pp. 666-677, 2011.

[27] J. J. Wang, W. Zhang, and B. J. S. Sanderson, "Altered mRNA expression related to the apoptotic effect of three xanthones on human melanoma SK-MEL-28 cell line," BioMed Research International, vol. 2013, Article ID 715603, 10 pages, 2013.

[28] Y. Mizushina, I. Kuriyama, T. Nakahara, Y. Kawashima, and H. Yoshida, "Inhibitory effects of $\alpha$-mangostin on mammalian DNA polymerase, topoisomerase, and human cancer cell proliferation," Food and Chemical Toxicology, vol. 59, pp. 793-800, 2013.

[29] S. Beninati, S. Oliverio, M. Cordella et al., "Inhibition of cell proliferation, migration and invasion of B16-F10 melanoma cells by $\alpha$-mangostin," Biochemical and Biophysical Research Communications, vol. 450, no. 4, pp. 1512-1517, 2014.

[30] A. Krajarng, S. Nilwarankoon, S. Suksamrarn, and R. Watanapokasin, "Antiproliferative effect of $\alpha$-mangostin on canine osteosarcoma cells," Research in Veterinary Science, vol. 93, no. 2, pp. 788-794, 2012.

[31] Y. Nakagawa, M. Iinuma, T. Naoe, Y. Nozawa, and Y. Akao, "Characterized mechanism of $\alpha$-mangostin-induced cell death: caspase-independent apoptosis with release of endonuclease$G$ from mitochondria and increased miR-143 expression in human colorectal cancer DLD-1 cells," Bioorganic and Medicinal Chemistry, vol. 15, no. 16, pp. 5620-5628, 2007.

[32] Y. Sánchez-Pérez, R. Morales-Bárcenas, C. M. García-Cuellar et al., "The $\alpha$-mangostin prevention on cisplatin-induced apoptotic death in LLC-PK1 cells is associated to an inhibition of ROS production and $\mathrm{p} 53$ induction," Chemico-Biological Interactions, vol. 188, no. 1, pp. 144-150, 2010.

[33] S. Zaman, R. Wang, and V. Gandhi, "Targeting the apoptosis pathway in hematologic malignancies," Leukemia and Lymphoma, vol. 55, no. 9, pp. 1980-1992, 2014.

[34] K. Brinkmann and H. Kashkar, "Targeting the mitochondrial apoptotic pathway: a preferred approach in hematologic malignancies?" Cell Death and Disease, vol. 5, no. 3, article e1098, 2014.

[35] Y.-H. Hsiao, C.-I. Lin, H. Liao, Y.-H. Chen, and S.-H. Lin, "Palmitic acid-induced neuron cell cycle G2/M arrest and 
endoplasmic reticular stress through protein palmitoylation in SH-SY5Y human neuroblastoma cells," International Journal of Molecular Sciences, vol. 15, no. 11, pp. 20876-20899, 2014.

[36] H. Li, J. Qin, G. Jin et al., "Overexpression of Lhx8 inhibits cell proliferation and induces cell cycle arrest in PC12 cell line," In Vitro Cellular \& Developmental Biology-Animal, vol. 51, no. 4, pp. 329-335, 2015.

[37] H. Kurose, M.-A. Shibata, M. Iinuma, and Y. Otsuki, "Alterations in cell cycle and induction of apoptotic cell death in breast cancer cells treated with $\alpha$-mangostin extracted from mangosteen pericarp," Journal of Biomedicine and Biotechnology, vol. 2012, Article ID 672428, 9 pages, 2012.

[38] K. Matsumoto, Y. Akao, K. Ohguchi et al., "Xanthones induce cell-cycle arrest and apoptosis in human colon cancer DLD-1 cells," Bioorganic and Medicinal Chemistry, vol. 13, no. 21, pp. 6064-6069, 2005. 


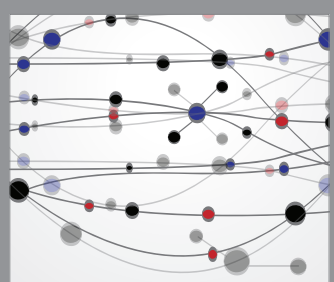

The Scientific World Journal
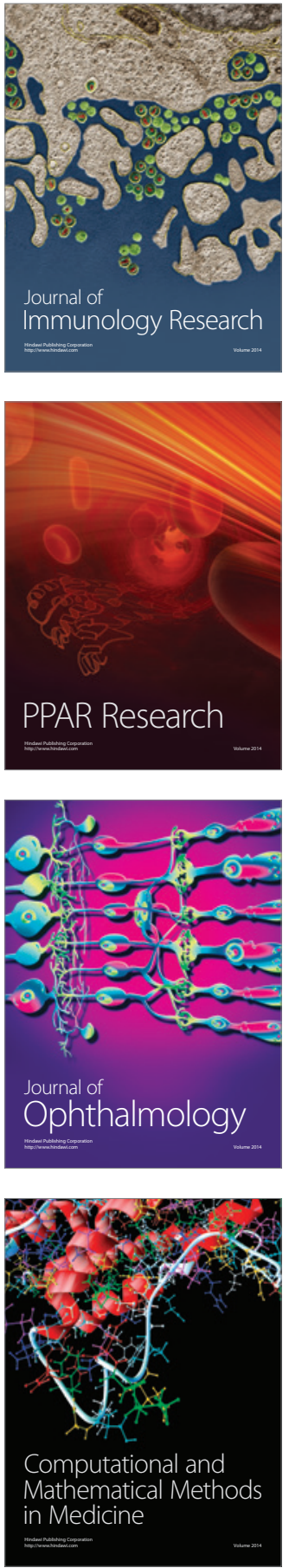

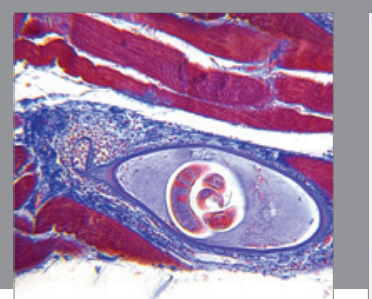

Gastroenterology Research and Practice

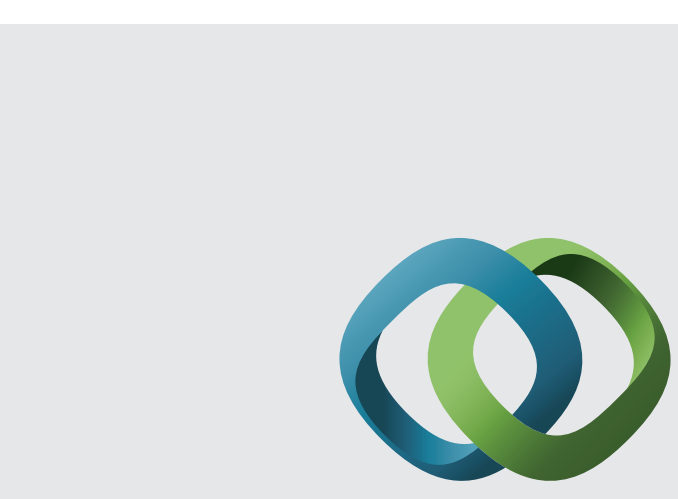

\section{Hindawi}

Submit your manuscripts at

http://www.hindawi.com
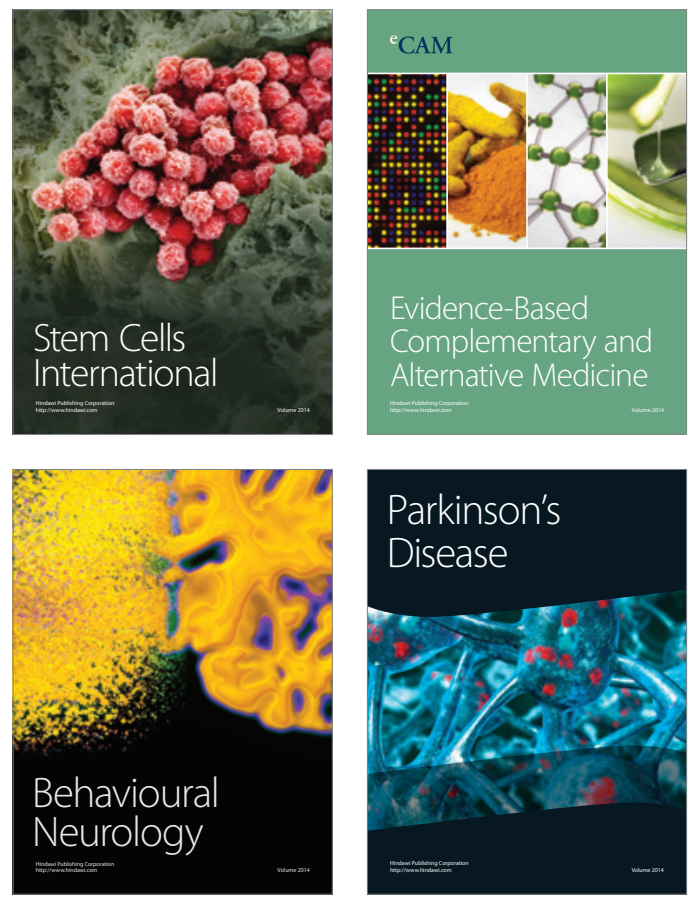
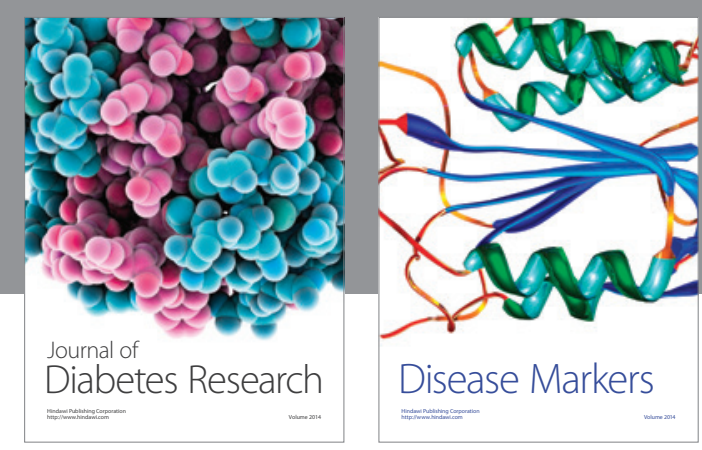

Disease Markers
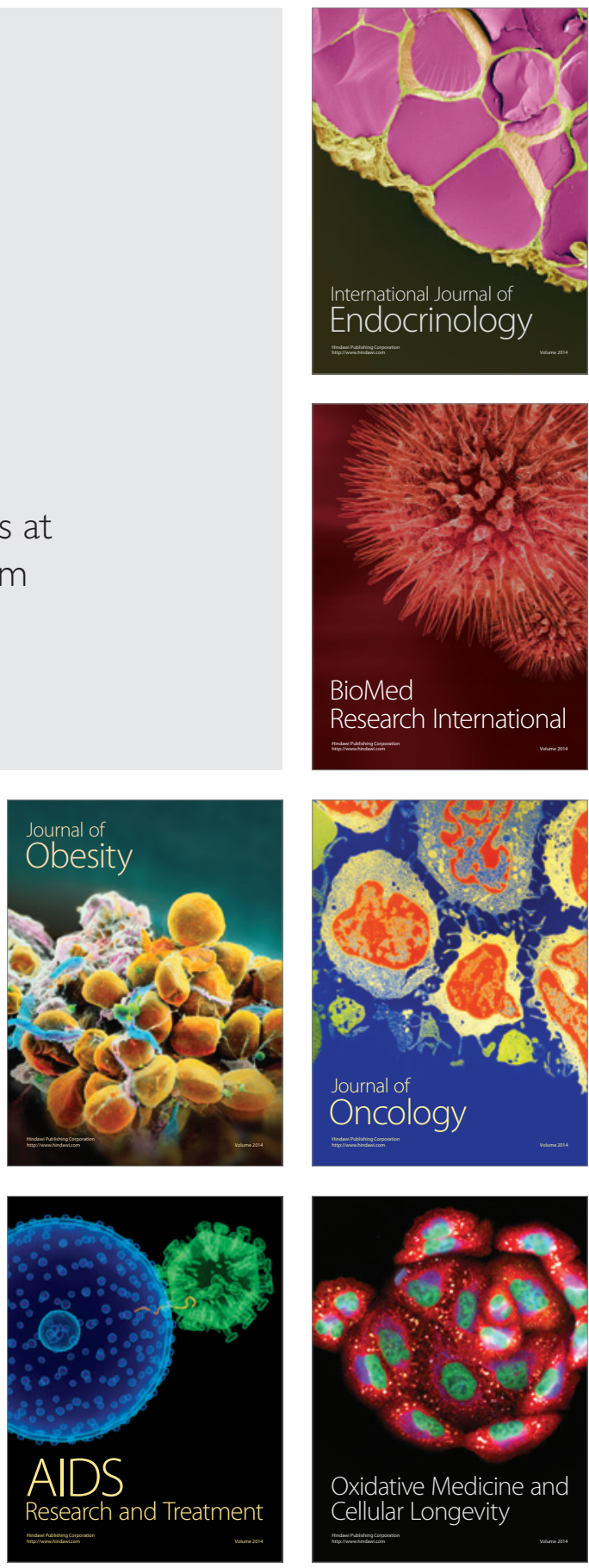